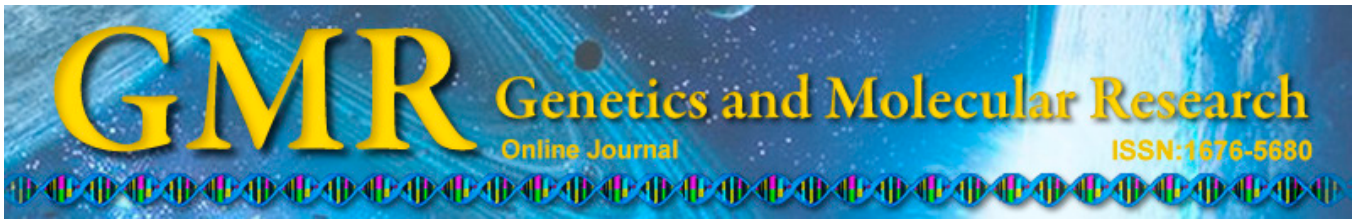

\title{
$P A X-9$ polymorphism may be a risk factor for hypodontia: a meta-analysis
}

\author{
W. Zhang, H.C. Qu and Y. Zhang \\ Department of Orthodontics, Hospital of Stomatology, \\ China Medical University, Shenyang, Liaoning, China \\ Corresponding author: Y. Zhang \\ E-mail: zgykdxzhangyang@126.com \\ Genet. Mol. Res. 13 (4): 9997-10006 (2014) \\ Received January 14, 2014 \\ Accepted June 2, 2014 \\ Published November 28, 2014 \\ DOI http://dx.doi.org/10.4238/2014.November.28.4
}

\begin{abstract}
To evaluate the association between paired box 9 (PAX9) gene polymorphisms and tooth agenesis in isolated humans, we performed a comprehensive meta-analysis. We examined 6 casecontrol studies, with a total of 855 hypodontia cases and 1201 healthy controls. The $\mathrm{G}$ allele and $\mathrm{G}$ carrier $(\mathrm{AG}+\mathrm{GG})$ of $\mathrm{A} 1031 \mathrm{G}$ were positively associated with hypodontia susceptibility. Similarly, the T allele and T carrier (CT + TT) of C912T and rs12881240 in the PAX9 gene also indicated an increased risk of hypodontia. In addition, the $\mathrm{C}$ allele and C carrier (CG + CC) of 718C, IVS2-109, rs4904210, and rs7143727 showed no significant association with oligodontia. The $\mathrm{G}$ allele and $\mathrm{G}$ carrier (AG + GG) of IVS2-41 in the $P A X 9$ gene were not related factors. Interestingly, the genotype $(\mathrm{AG}+\mathrm{GG})$ of IVS2-54 in the $P A X 9$ gene may be a protective factor for oligodontia (odds ratio $=0.21,95 \%$ confidence interval $=0.07-0.63, \mathrm{P}=0.005)$. However, no significant differences were found in the allele frequency of IVS2-54 in the $P A X 9$ polymorphism between controls and subjects with sporadic tooth agenesis. In conclusion, our meta-analysis results revealed 4 genetic sites of the $P A X 9$ gene involved in hypodontia cases, of which 3 sites may be risk factors and 1 may have a protective role.
\end{abstract}

Key words: Genetic polymorphism; Hypodontia; Meta-analysis; PAX9 


\section{INTRODUCTION}

Hypodontia, or tooth agenesis, which is the congenital absence of one or a few teeth, is a common condition in human dentition. It affects up to $20 \%$ of people worldwide and includes 2 types, syndromic or non-syndromic, and can occur as a familial (autosomal-dominant, autosomal-recessive, or cross-linked) or isolated sporadic trait (Vastardis, 2000). During the long process of dental development, complex interactions between genetic, epigenetic, and environmental factors cause dental anomalies (Brook, 2009). These factors are variable, and completed factors occurring over time are multi-factorial, multilevel, multidimensional, and progressive.

The paired box 9 (PAX9) gene encodes for transcription factors that are expressed in the dental mesenchyme at all stages of odontogenesis, including the initiation, bud, cap, and bell stages (Vainio et al., 1993; Peters et al., 1998). Protein products of this gene serve as transcription factors responsible for the cross-talk between epithelial and mesenchymal tissues. In addition, they are essential for establishing the odontogenic potential of the mesenchyme (Peters and Balling, 1999; Tucker and Sharpe, 1999; Jernvall and Thesfleff, 2000; ScarelCaminaga et al., 2003). Pax9-deficient mice were shown to lack pharyngeal pouch derivates and teeth and exhibited severe craniofacial and limb abnormalities (Peters et al., 1998).

Polymorphisms are a mechanism by which individuals may exhibit variations within the range of what is considered to be biologically normal. A strong association exists between gene polymorphisms and disease susceptibility. Most polymorphisms are single-nucleotide exchanges that occur at a high frequency in the human genome and may affect gene function. These types of variants are regarded as hypomorphic and accompany clinical symptoms showing reduced activity but not a complete loss in activity; these 'risk alleles' can occur either in coding or non-coding regions. The mechanism affects the amount of protein produced rather than the protein function (Nieminen, 2009). Single-nucleotide polymorphisms (SNPs) are the most common form of human genetic variation and may contribute to individual susceptibility to hypodontia.

Over the past few years, several growth and transcription factors have been shown to be expressed in developing teeth (Thesleff, 1996; Jernvall and Thesleff, 2000). For example, mutations or polymorphisms in the $P A X 9$ gene are responsible for congenital or familial forms of tooth agenesis. However, why most cases of non-syndromic or sporadic forms of tooth agenesis occur in humans remains unknown. We performed a meta-analysis to determine the mechanisms of tooth angenesis.

\section{MATERIAL AND METHODS}

\section{Literature search}

We performed an extensive electronic search of the PubMed, Cochrane Library, Embase, Web of Science, Springerlink, China National Knowledge Infrastructure, and the Chinese Biomedical Database to identify relevant studies published until December 6, 2013. Search terms included ["pax9" or "PAX9" (Mesh)] or ["SNPs" or "SNP" or "polymorphism, genetic" (Mesh)], and ["hypodontia" or "oligodontia" or "tooth agenesis" (Mesh)]. References in the eligible studies and textbooks were also manually reviewed to identify other potentially eligible studies. 


\section{Inclusion and exclusion criteria}

Studies included were required to meet the following criteria: 1) the type of study should be a case-control study; 2) these case-control studies should focus on the association between $P A X 9$ genetic polymorphisms and hypodontia risk; 3) all patients were diagnosed with hypodontia based on panoramic radiographs and careful examinations of their clinical charts; 4) the frequencies of alleles or genotypes in case and control groups could be extracted; and 5) the language of publication was English. Studies were excluded when they were: 1) not case-control studies examining PAX9 genetic polymorphisms and hypodontia risk; 2) included patients with other anomalies beyond agenesis; 3 ) based on incomplete or irrelevant data; 4) reported irrelevant or overlapping data; or 5) if they were meta-analyses, letters, reviews, or editorials.

\section{Data extraction}

Using a standardized form, 2 reviewers (W.Z. and H.C.Q.) extracted data from studies published independently. The following information was extracted from each article, including: first author, year of publication, country, language, ethnicity, study design, diagnostic criteria, source of cases and controls, number of cases and controls, mean age, sample, number of missing teeth, genotype methods, polymorphism genotype frequency, and evidence of HardyWeinberg equilibrium (HWE) in controls. In cases of conflicting evaluations, an agreement was reached after a discussion with a third reviewer (Y.Z.).

\section{Quality assessment of studies included}

Two reviewers (W.Z. and H.C.Q.) independently assessed the quality of selected papers according to a modified Strengthening the Reporting of Observational Studies in Epidemiology quality score system (von Elm et al., 2007; Zhang et al., 2011). Forty assessment items related to quality appraisal were used in this meta-analysis, with a scale ranging from 0-40. Scores of 0-20, 20-30, and 30-40 were defined as low, moderate, and high quality, respectively. Disagreement was resolved through discussion with a third reviewer (Y.Z.).

\section{Statistical analysis}

The odds ratio (OR) and $95 \%$ confidence interval $(95 \% \mathrm{CI})$ were calculated using Review Manager Version 5.1.6 [provided by Cochrane Collaboration; http://ims.cochrane.org/ revman/download (accessed 9 August 2013)] and STATA Version 12.0 (Stata Corp; College Station, TX, USA). Between-study variations and heterogeneities were estimated using Cochran's Q statistic (Higgins and Thompson, 2002; Zintzaras and Ioannidis, 2005). A P value of $\leq 0.05$ was considered to be a manifestation of statistically significant heterogeneity.

We also quantified the effect of heterogeneity using the $\mathrm{I}^{2}$ test. $\mathrm{I}^{2}$ represents the proportion of inter-study variability that can be attributed to heterogeneity rather than to chance with the range of $0-100 \%$. $\mathrm{I}^{2}$ values of 25,50 , and $75 \%$ were defined as low, moderate, and high estimates, respectively. When a significant $\mathrm{Q}$ test $(\mathrm{P}<0.10)$ or an $\mathrm{I}^{2}$ of $>50 \%$ indicated heterogeneity across studies, the random-effect model was used for meta-analysis; otherwise, 
the fixed-effect model was used. We tested whether genotype frequencies of controls were in HWE using the chi-squared test. Sensitivity analysis was mainly performed through sequential omission of individual studies.

Publication bias was investigated using Begger's funnel plot, and funnel plot asymmetry was assessed with the Egger linear regression test (Peters et al., 2006). Statistical significance was reached when the $\mathrm{P}$ value of the Egger test was $<0.05$. All $\mathrm{P}$ values were 2 -sided. To ensure the reliability and accuracy of the results, 2 reviewers (W.Z. and H.C.Q.) populated the data in the statistical software programs independently and obtained the same results.

\section{RESULTS}

\section{Characteristics of studies included}

The search strategy retrieved 102 potentially relevant studies. According to the inclusion criteria, 6 studies (Peres et al., 2005; Pawlowska et al., 2010; Pinho et al., 2010; PaixãoCôrtes et al., 2011; Liu et al., 2012; Wang et al., 2013) were included in the meta-analysis and 96 were excluded. The flow chart of study selection is shown in Figure 1. The 6 case-control studies selected included 855 cases and 1201 healthy controls evaluating the relationship between $P A X 9$ genetic polymorphisms and hypodontia. The publication year of involved studies ranged from 2005-2013. All patients fulfilled the diagnostic criteria of hypodontia by panoramic radiographs and careful examination of their clinical charts. The source of controls was a healthy population. Nine SNPs in the PAXY gene were addressed. The HWE test was performed on the genotype distribution of the controls in all studies included and all were found to be in HWE $(\mathrm{P}>0.05)$. All quality scores of studies included were $>20$ (moderate to high quality). The characteristics and methodological quality of the studies included are summarized in Table 1. The genotype distributions of $P A X 9$ genetic polymorphisms in case and control groups are shown in Figures 2-4.

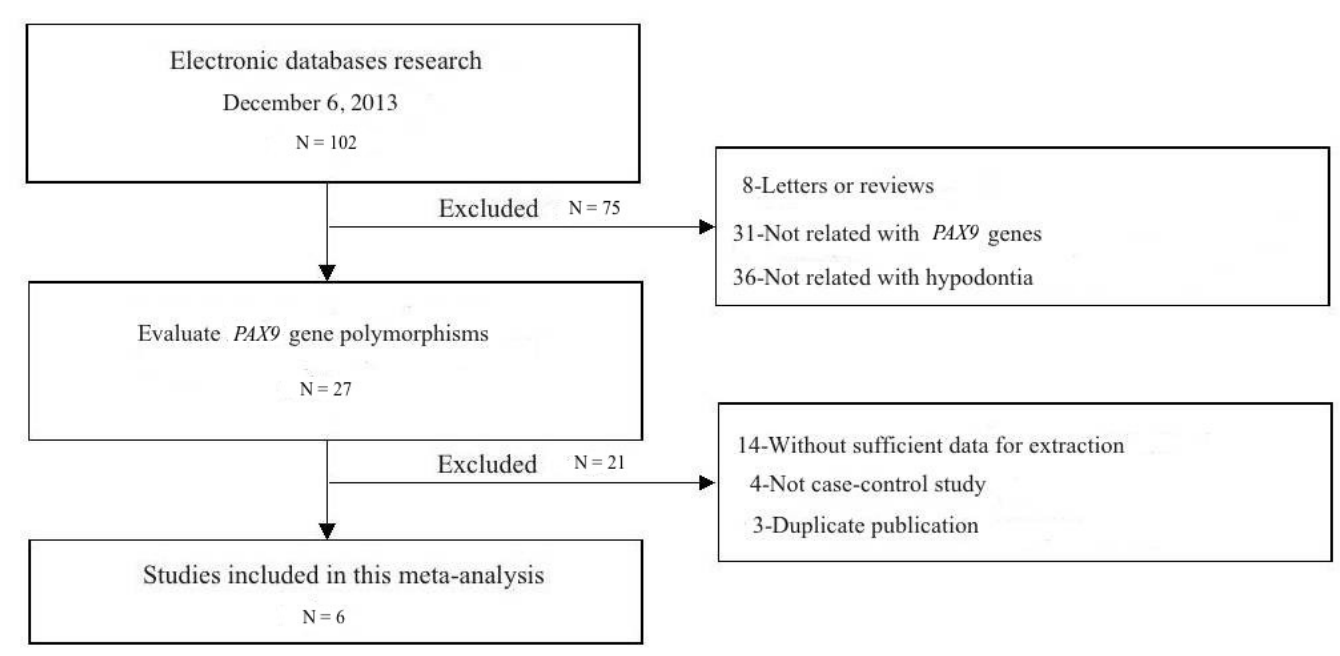

Figure 1. Flow chart showing study selection procedure. 
Table 1. Characteristics of individual studies in this meta-analysis.

\begin{tabular}{lccclc}
\hline Author & Year & Case (number) & Control (number) & Gene site & Quality score \\
\hline Peres et al. & 2005 & 102 & 106 & G-1031A & C-912T \\
Pinho et al. & 2010 & 20 & & G718C & 23 \\
Pawlowska et al. & 2010 & 38 & 100 & IVS2-54 & IVS2-109 \\
& & & & IVS2-41 & rs714373727 \\
Paixão-Côrtes et al. & 2011 & 100 & 100 & rs12881240 & rs4904210 \\
& & & & rs4904210 \\
Liu et al. & 2012 & 117 & 98 & rs12881240 \\
Wang et al. & 2013 & 50 & & rs4904210 & 22 \\
& & & & & 25 \\
\hline
\end{tabular}

PAX-9

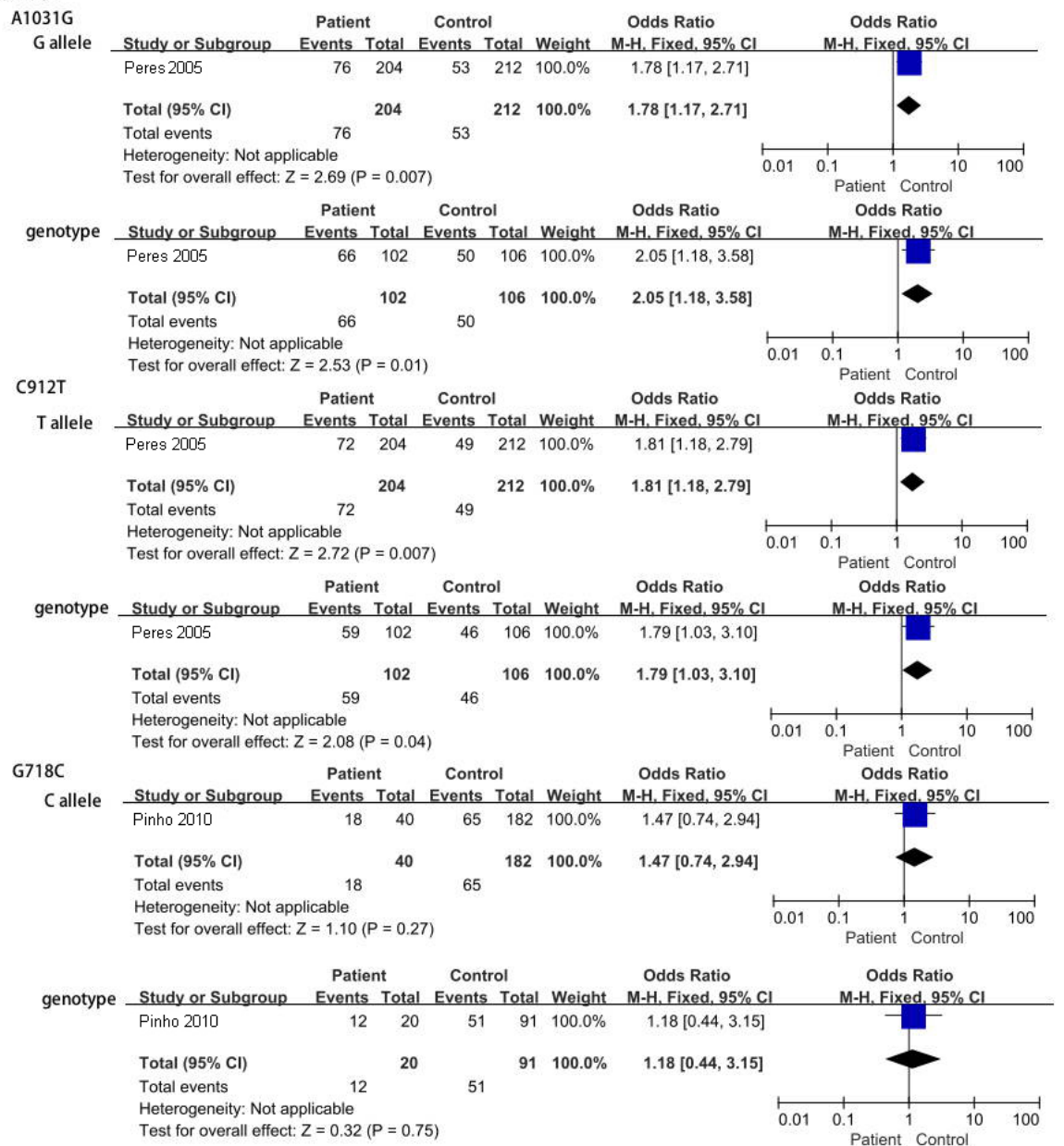

Figure 2. A1031G, C912T, and G718C genotype distributions of $P A X 9$ genetic polymorphisms in case and control groups. 


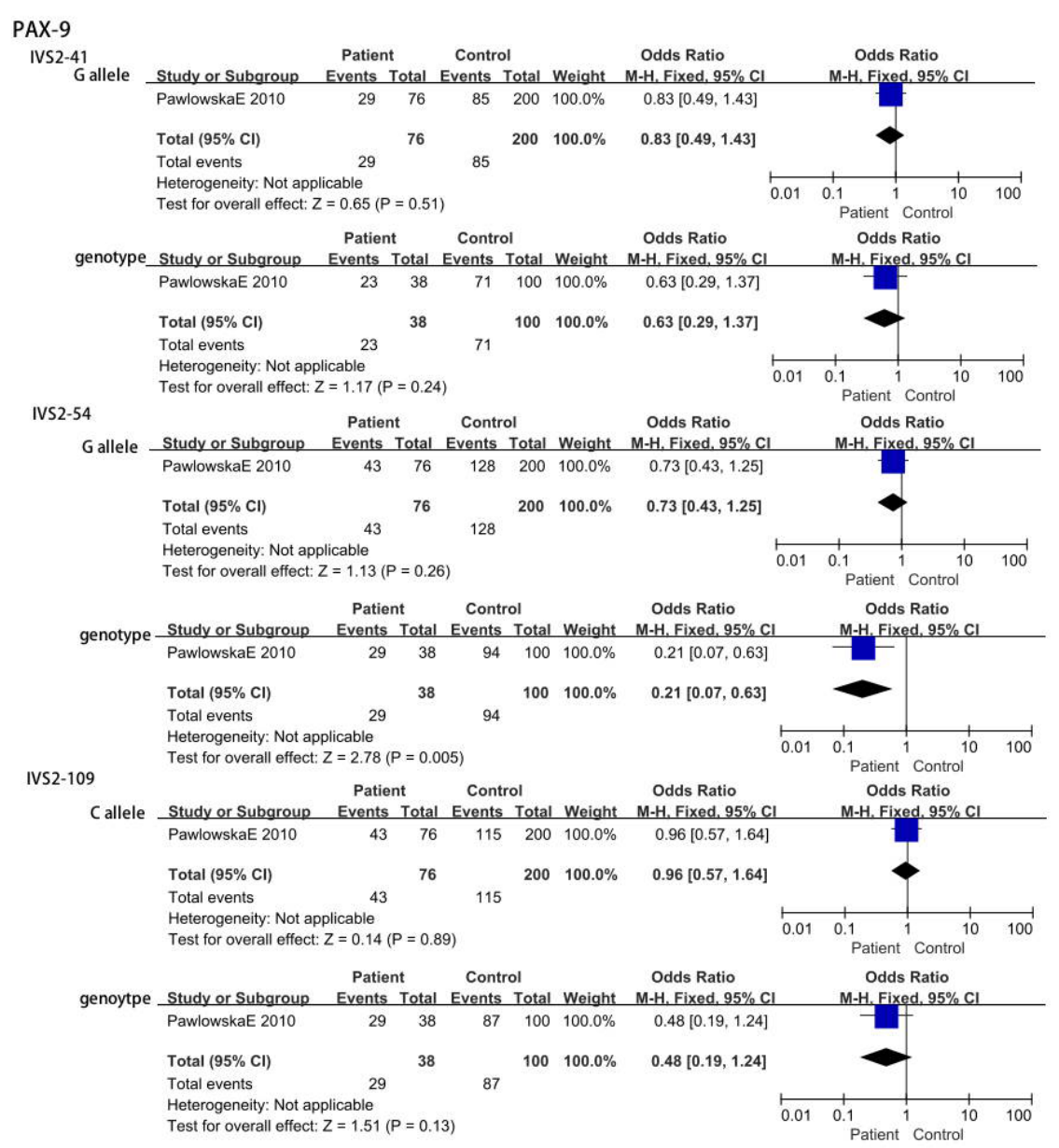

Figure 3. IVS2-41, IVS2-54, and IVS2-109 genotype distributions of $P A X 9$ genetic polymorphisms in case and control groups.

\section{Association between $P A X 9$ gene polymorphisms and hypodontia}

As shown in Figure 3, the meta-analysis revealed a significant difference in the $\mathrm{G}$ allele and G carrier (AG + GG) of IVS-41 and IVS2-54 in the PAX9 gene between patients with tooth agenesis and healthy subjects $(\mathrm{OR}=0.83,95 \% \mathrm{CI}=0.49-1.43, \mathrm{P}=0.51 ; \mathrm{OR}=0.63$, $95 \% \mathrm{CI}=0.29-1.37, \mathrm{P}=0.24 ; \mathrm{OR}=0.73,95 \% \mathrm{CI}=0.43-1.25, \mathrm{P}=0.26 ; \mathrm{OR}=0.21,95 \% \mathrm{CI}=$ $0.07-0.63, \mathrm{P}=0.005$, respectively), indicating that those with the $\mathrm{G}$ allele and $\mathrm{G}$ carrier (AG $+\mathrm{GG}$ ) of IVS-41 and IVS2-54 in the PAX9 gene polymorphism may have an increased risk of hypodontia. For the C allele and C carrier (CG + CC) of 718C, IVS2-109, rs4904210, and rs7143727 in the $P A X 9$ gene, no significant difference was observed $(\mathrm{OR}=1.47,95 \% \mathrm{CI}=$ $0.74-2.94, \mathrm{P}=0.27 ; \mathrm{OR}=1.18,95 \% \mathrm{CI}=0.44-3.15, \mathrm{P}=0.75 ; \mathrm{OR}=0.96,95 \% \mathrm{CI}=0.57-1.64$, $\mathrm{P}=0.89 ; \mathrm{OR}=0.48,95 \% \mathrm{CI}=0.19-1.24, \mathrm{P}=0.13 ; \mathrm{OR}=1.07,95 \% \mathrm{CI}=0.68-1.69, \mathrm{P}=0.76$; $\mathrm{OR}=1.17,95 \% \mathrm{CI}=0.81-1.70, \mathrm{P}=0.40 ; \mathrm{OR}=7.22,95 \% \mathrm{CI}=0.37-141.52, \mathrm{P}=0.19 ; \mathrm{OR}=$ 
$13.83,95 \% \mathrm{CI}=0.77-248.79, \mathrm{P}=0.07$, respectively). In addition, the $\mathrm{T}$ allele and $\mathrm{T}$ carrier (CT $+\mathrm{TT})$ of rs12881240 also showed no association with hypodontia susceptibility $(\mathrm{OR}=1.81$, $95 \% \mathrm{CI}=1.18-2.79, \mathrm{P}=0.007 ; \mathrm{OR}=1.79,95 \% \mathrm{CI}=1.03-3.10, \mathrm{P}=0.04)$. However, the $\mathrm{G}$ allele and $\mathrm{G}$ carrier $(\mathrm{AG}+\mathrm{GG})$ of A1031G and the T allele and T carrier (CT + TT) of C912T in the $P A X 9$ gene were positively associated with hypodontia $(\mathrm{OR}=1.78,95 \% \mathrm{CI}=1.17-2.71, \mathrm{P}$ $=0.007 ; \mathrm{OR}=2.05,95 \% \mathrm{CI}=1.18-3.58, \mathrm{P}=0.01 ; \mathrm{OR}=1.81, \mathrm{CI}=1.18-2.79, \mathrm{P}=0.007 ; \mathrm{OR}$ $=1.79,95 \% \mathrm{CI}=1.03-3.10, \mathrm{P}=0.04$; respectively). The significance of the pooled $\mathrm{OR}$ in all individual analyses was not influenced excessively by omitting any single study.

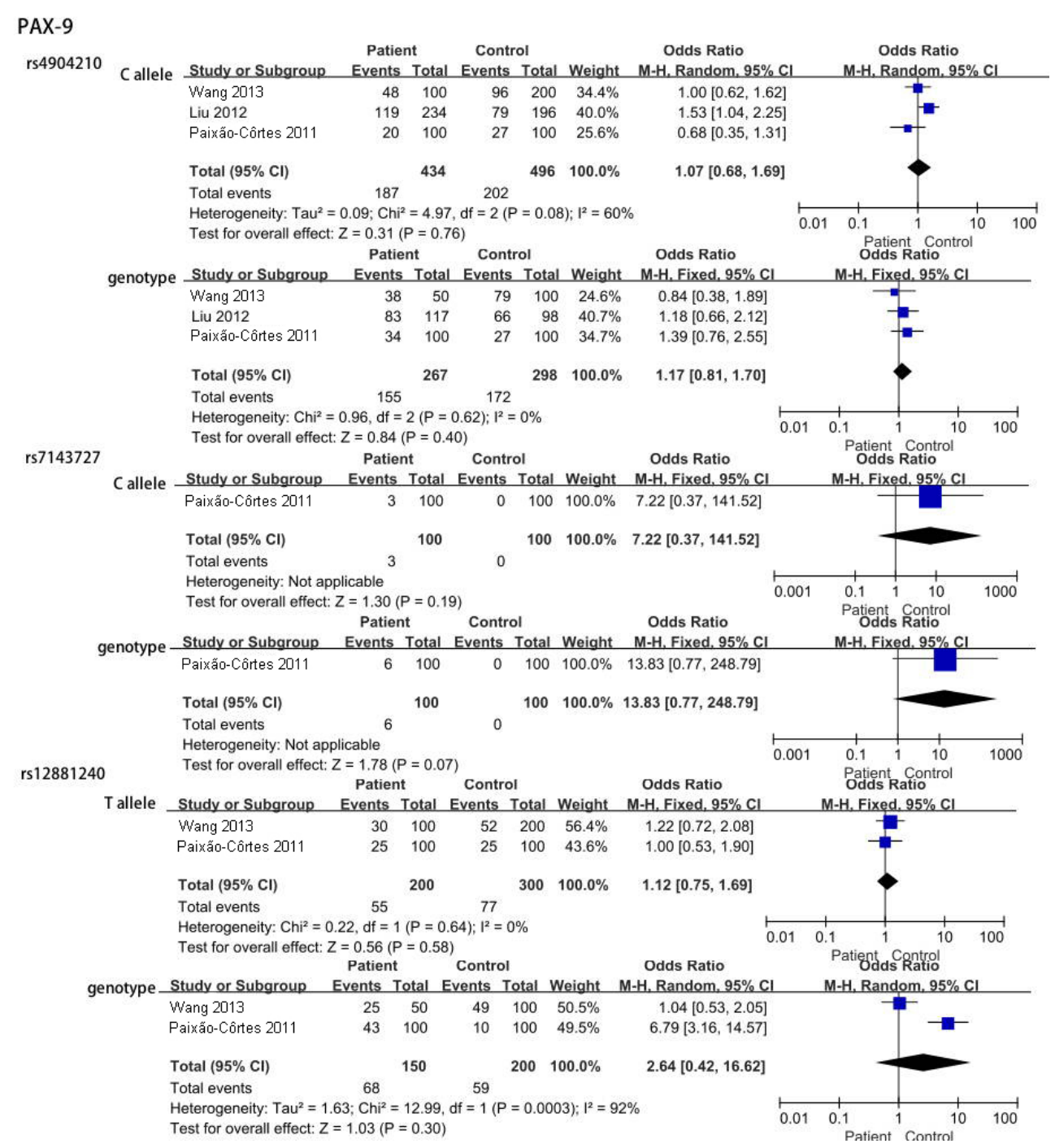

Figure 4. rs4904210, rs7143727, and rs12881240 genotype distributions of $P A X 9$ genetic polymorphisms in case and control groups. 


\section{Publication bias}

Publication bias of the literature was assessed using Begger's funnel plot and the Egger linear regression test. The Egger linear regression test was used to measure the asymmetry of the funnel plot. All graphical funnel plots of the included studies were symmetrical (Figures 5). The Egger test also showed that there was no publication bias.
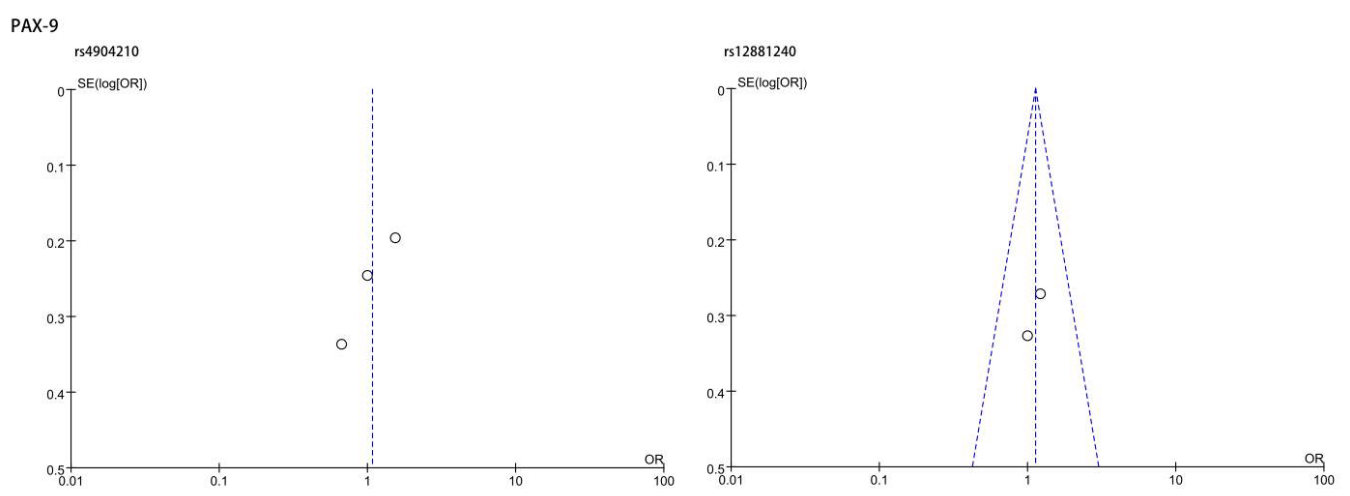

Figure 5. Begger's funnel plot of publication bias.

\section{DISCUSSION}

Hypodontia of the human dentition, caused by simultaneous mutations in different genes, may be an oligogenetic trait. According to our results, $33 \%$ of subjects who received orthodontic treatment had agenesis of one or more teeth. The tooth with the highest agenesis frequency was the third molar, followed by the lower premolars and upper lateral incisors. In fact, teeth are among the most important models in the field of evolutionary developmental biology linking the molecular strategies controlling organ development and morphological evolution (Line, 2003). They also link development with the generation of novelty in mammalian teeth (Polly, 2000). As with most evolutionary changes, tooth agenesis results from the loss of 1 or 2 elements. In most cases, oligodontia of the human dentition may be an oligogenetic trait resulting from simultaneous mutation of different type of genes. In addition, polymorphic genetic loci have been directly associated with morphological variation in non-vertebrates. It is well-established that morphological changes among and within species are ultimately determined by genetic interference during development because small changes during the developmental process can produce large changes in adult morphology (Kim et al., 2000; Raff, 2000).

Recent studies have shown that polymorphisms at specific sites of the PAX9 gene were associated with hypodontia in humans, supporting the hypothesis that the mutation causes oligodontia through a pathogenic mechanism. Kangas et al. (2004) reported that dental anomalies, which generally include size and shape alterations of teeth, tooth agenesis, or supernumerary teeth, were determined based on a set of genes in tooth development. However, 2 years later, $P A X 9$ gene mutations were ruled out in a number of instances with severe oligodontia (Gerits et al., 2006). These mutations, however, only partially account for the development of tooth agenesis (Chranowska et al., 1990; Fryns et al., 1990; Vieira et al., 2004). Although the 
case-control results showed no significant differences and the exact mechanism has not been fully elucidated, genetic factors are thought to play a central role in tooth agenesis.

Our meta-analysis included 6 independent case-control studies to examine the association between $P A X 9$ gene polymorphisms and hypodontia. Our fixed model analysis showed that the $\mathrm{G}$ allele and $\mathrm{G}$ carrier $(\mathrm{AG}+\mathrm{GG})$ of $\mathrm{A} 1031 \mathrm{G}$ in the $P A X 9$ gene may increase the risk of hypodontia and may be risk factors for the susceptibility to hypodontia. Similarly, the T allele and T carrier (CT + TT) of C912T and rs12881240 in the PAX9 gene were positively associated with hypodontia susceptibility. In addition, the $\mathrm{C}$ allele and $\mathrm{C}$ carrier $(\mathrm{CG}+\mathrm{CC})$ of 718C, IVS2-109, rs4904210, and rs7143727 showed no significant association with oligodontia. The $\mathrm{G}$ allele and $\mathrm{G}$ carrier $(\mathrm{AG}+\mathrm{GG})$ of IVS2-41 were identified in the PAX9 gene but were not related to oligodontia. Interestingly, we identified protective roles for the genotype $(\mathrm{AG}+\mathrm{GG})$ of IVS2-54 in the development of teeth, which is a protective factor in the formation of hypodontia $(\mathrm{OR}=0.21,95 \% \mathrm{CI}=0.07-0.63, \mathrm{P}=0.005)$. However, no significant differences were found in the allele frequency of IVS2-54 in the PAX9 polymorphism between controls and subjects with sporadic tooth agenesis.

Similar to other meta-analyses, there are some limitations to our study. First, because the eligible number of studies in this meta-analysis was small, these results require further investigation. In addition, the number of studies and subjects according to the references included in the meta-analysis was limited, and some relevant studies were excluded from our analysis because incomplete raw data were included. Furthermore, we could not address the sources of heterogeneity among all studies. Fourth, a meta-analysis is a retrospective study that is subject to methodological limitations. Fifth, although the cases and controls of each study were well defined with similar inclusion criteria, factors that were not taken into account may have influenced our results. Importantly, our meta-analysis was based on unadjusted OR estimates because not all published studies presented adjusted ORs or presented ORs adjusted by the same potential confounders such as age, gender, ethnicity, and exposure. In conclusion, this meta-analysis of 6 case-control studies demonstrated that $P A X 9$ genetic polymorphisms are involved in the pathogenesis of tooth agenesis. Because of the limited number of studies published in this field, the current available evidence remains limited. Therefore, we emphasize the necessity of conducting large studies with adequate methodological quality and proper control of confounding factors to obtain valid results.

\section{REFERENCES}

Brook AH (209). Multilevel complex interactions between genetic, epigenetic and environmental factors in the aetiology of anomalies of dental development. Arch. Oral Biol. 54 (Suppl 1): 3-17.

Chranowska KH, Krajewska-Walasek M, Rump Z, Wisniewski L, et al. (1990). Anodontia as the sole clinical sign of the ectrodactylyectodermal dysplasia-cleft lip (EEC) syndrome. Genet. Couns. 1: 67-73.

Fryns JP, Legius E, Dereymaeker AM and Van den Berghe H (1990). EEC syndrome without ectrodactyly: report of two new families. J. Med. Genet. 27: 165-168.

Gerits A, Nieminen P, De Muynck S and Carels C (2006). Exclusion of coding region mutations in MSX1, PAX9 and AXIN2 in eight patients with severe oligodontia phenotype. Orthod. Craniofac. Res. 9: 129-136.

Higgins JP and Thompson SG (2002). Quantifying heterogeneity in a meta-analysis. Stat. Med. 21: 1539-1558.

Jernvall J and Thesleff I (2000). Reiterative signaling and patterning during mammalian tooth morphogenesis. Mech. Dev. 92: 19-29.

Kangas AT, Evans AR, Thesleff I and Jernvall J (2004). Nonindependence of mammalian dental characters. Nature 432: 211-214.

Kim J, Kerr JQ and Min GS (2000). Molecular heterochrony in the early development of Drosophila. Proc. Natl. Acad. Sci. USA 97: 212-216. 
Line SR (2003). Variation of tooth number in mammalian dentition: connecting genetics, development and evolution. Evol. Dev. 5: 295-304.

Liu H, Zhang J, Song S, Zhao H, et al. (2012). A case-control study of the association between tooth-development gene polymorphisms and non-syndromic hypodontia in the Chinese Han population. Eur. J. Oral Sci. 120: 378-385.

Nieminen P (2009). Genetic basis of tooth agenesis. J. Exp. Zool. B Mol. Dev. Evol. 312B: 320-342.

Paixão-Côrtes VR, Braga T, Salzano FM, Mundstock K, et al. (2011). PAX9 and MSX1 transcription factor genes in nonsyndromic dental agenesis. Arch. Oral Biol. 56: 337-344.

Pawlowska E, Janik-Papis K, Poplawski T, Blasiak J, et al. (2010). Mutations in the PAX9 gene in sporadic oligodontia. Orthod. Craniofac. Res. 13: 142-152.

Peres RC, Scarel-Caminaga RM, do Espírito Santo AR and Line SR (2005). Association between PAX-9 promoter polymorphisms and hypodontia in humans. Arch. Oral Biol. 50: 861-871.

Peters H and Balling R (1999). Teeth. Where and how to make them. Trends Genet. 15: 59-65.

Peters H, Neubüser A, Kratochwil K and Balling R (1998). Pax9-deficient mice lack pharyngeal pouch derivatives and teeth and exhibit craniofacial and limb abnormalities. Genes Dev. 12: 2735-2747.

Peters JL, Sutton AJ, Jones DR, Abrams KR, et al. (2006). Comparison of two methods to detect publication bias in metaanalysis. JAMA 295: 676-680.

Pinho T, Silva-Fernandes A, Bousbaa H and Maciel P (2010). Mutational analysis of MSX1 and PAX9 genes in Portuguese families with maxillary lateral incisor agenesis. Eur. J. Orthod. 32: 582-588.

Polly PD (2000). Development and evolution occlude: evolution of development in mammalian teeth. Proc. Natl. Acad. Sci. USA 97: 14019-14021.

Raff RA (2000). Evo-devo: the evolution of a new discipline. Nat. Rev. Genet. 1: 74-79.

Scarel-Caminaga RM, Pasetto S, da Silva ER and Peres RCR (2003). Genes and tooth development: reviewing the structure and function of some key players. Braz. J. Oral Sci. 7: 339-347.

Thesleff I (1996). Two genes for missing teeth. Nat. Genet. 13: 379-380.

Tucker AS and Sharpe P (1999). Molecular genetics of tooth morphogenesis and patterning of the right shape in the right place. J. Dent. Res. 78: 826-834.

Vainio S, Karavanova I, Jowete A and Thesleff I (1993). Identification of BMP-4 as a signal mediating secondary induction between epithelial and mesenchymal tissues during early tooth development. Cell 75: 45-48.

Vastardis H (2000). The genetics of human tooth agenesis: new discoveries for understanding dental anomalies. Am. J. Orthod. Dentofac. Orthop. 117: 650-656.

Vieira AR, Meira R, Modesto A and Murray JC (2004). MSX1, PAX9, and TGFA contribute to tooth agenesis in humans. J. Dent. Res. 83: 723-727.

von Elm E, Altman DG, Egger M, Pocock SJ, et al. (2007). STROBE Initiative: The Strengthening the Reporting of Observational Studies in Epidemiology. Epidemiology 18: 800-804.

Wang J, Xu Y, Chen J, Wang F, et al. (2013). PAX9 polymorphism and susceptibility to sporadic non-syndromic severe anodontia: a case-control study in southwest China. J. Appl. Oral Sci. 21: 256-264.

Zhang L, Liu JL, Zhang YJ and Wang H (2011). Association between HLA-B*27 polymorphisms and ankylosing spondylitis in Han populations: a meta-analysis. Clin. Exp. Rheumatol. 29: 285-292.

Zintzaras E and Ioannidis JP (2005). Heterogeneity testing in meta-analysis of genome searches. Genet. Epidemiol. 28: 123-137. 